\title{
11 Assessing Responsible Research and Innovation (RRI) systems in the digital age
}

\author{
Claudia Werker
}

\subsection{Introduction}

In the past few decades the processes as well as the assessment of research and innovation have become increasingly complicated. There have been three major factors driving this development. First, despite innovation and technology sometimes displaying a dark side (Gebauer, Füller, \& Pezzei, 2013), they have become core to solving commercial, economic and societal problems in a responsible way (Stilgoe, Owen, \& Macnaghten, 2013). Accordingly, policy has been more and more concentrating on Responsible Research and Innovation (RRI), i.e. on marrying socio-economic change with ethical concerns (European Commission, 2013). Second, the development and deployment of all-encompassing fields, such as biotechnology, information and communication technologies as well as nanotechnology, have required a deeper integration of industry, academia, civil society and government (Etzkowitz \& Viale, 2010; European_Commission, 2012). Third, digitization, i.e. the transformation of established patterns of socioeconomic life driven by processes of converting information into digital format and analysing them at large scale, has been infiltrating all walks of life (Loebbecke \& Picot, 2015): it changes the way we connect to others, exchange information and knowledge, take decisions, work and shop. It also fundamentally alters research and innovation.

In this chapter, I investigate the opportunities and challenges of assessing RRI systems in the digital age. I start with showing why RRI needs a system approach and introduce the concept of RRI systems (Section 11.2). Then, I turn to how innovation systems have been assessed so far and summarize the key steps in a scheme (Section 11.3.1) that serves as a starting point for developing a new scheme adding responsibility to the innovation system and its assessment (Section 11.3.2). After that, I show that in the digital age big data alters the assessment of RRI systems severely (Section 11.4.1) and discuss the arduous challenges and promising solutions resulting from that (Section 11.4.2). Finally, I briefly summarize the results of my analysis, elaborate on their implications for the various stakeholders and provide a fundamental open research question emerging from them (Section 11.5). 


\subsection{RRI requires a system approach}

RRI is at the heart of better employing and exploiting the potential of science, technology and innovation by considering and incorporating values, i.e. "things worth striving for" (Taebi, Correljé, Cuppen, Dignum, \& Pesch, 2014, p. 119), societal needs as well as economic opportunities (European Commission, 2013; Taebi et al., 2014). "[I]n an ideal situation, responsible innovation can best be conceptualized as an endorsement of the relevant values during the innovation process" (Taebi et al., 2014, p. 118).

In order to realize RRI all stakeholders need to be part of the process (Taebi et al., 2014). In particular, not only innovative agents, i.e. those actively influencing research and innovation, are relevant for the RRI process but also all other stakeholders which might be affected by either the process or the outcome. In order to be able to understand the implications of the research and innovation processes, these stakeholders not only have to identify the purposes and trajectories of research and innovation but also their effects and alternatives (Forsberg, Shelley-Egan, Ladikas, \& Owen, 2018). Based on these insights stakeholders are able to assess research and innovation in the light of their values. In fact, value implications caused by new technologies are core to processes leading to responsible innovation as they can either stimulate or undermine values (van de Poel, 2009).

RRI requires a system approach for two major reasons. The first reason points to the necessity to analyse research and innovation from a system perspective in general terms. In recent decades all-encompassing fields, such as biotechnology, information and communication technologies as well as nanotechnology, have emerged and have required a deeper integration of industry, academia, the civil society and government (Etzkowitz \& Viale, 2010; European Commission, 2012). A typical issue addressed by such a deeper integration is a missing fit between academic capabilities and industrial needs. Deeper integration means that innovative agents engage in reciprocal relationships by considering the point of view of the other agents in order to enhance their performance.

The second reason for employing a system perspective emerges from the nature of RRI. Developing shared values about the process and outcomes of research and innovation requires integration of the values of all relevant stakeholders (European Commission, 2013; Taebi et al., 2014). While the values of stakeholders can substantially differ, shared values can only emerge if stakeholders eventually agree on them. Developing shared values is non-trivial, because stakeholders differ regarding both their power and their legitimacy (Mitchell, Agle, \& Wood, 1997). In the context of RRI processes, the question about the power positions clarifies who depends on whom and who can influence or even pressure others to act against their own values. The question about legitimacy touches the very heart of shared values, because it clarifies what socially accepted and expected behaviour of the various stakeholders is. Therefore, the institutions guiding stakeholders' behaviour 
and the relationships between them are core to RRI processes. Furthermore, these processes change in time, so that the dynamics of relationships and of institutions supporting RRI are centre-stage (Forsberg et al., 2018). To find RRI, i.e. to base jointly acceptable solutions in research and innovation on shared values, entails that all stakeholders communicate and possibly collaborate. Analysing these processes means investigating all stakeholders as well as the dynamics of their relationships and the supporting institutions, i.e. using a system approach.

As shown above, analysing and realizing RRI require a system approach. While the term responsible innovation system has been used in passing to call for "a broader imaginary of a responsible innovation system involving reconfiguration of knowledge flows and institutions" (Forsberg et al., 2018, p. 10), to my knowledge, it has not been comprehensively defined or used for analysis so far. In the following, in order to capture all relevant stakeholders of RRI and the way their values affect their activities, relationships and supporting institutions I will use the term RRI system.

\subsection{Assessment of RRI systems}

First, I show how innovation systems have been assessed so far and provide a scheme of how to assess an innovation system (Section 11.3.1). Following that, I augment this scheme with responsibility. I do so by pointing at those elements in the assessment of RRI systems that are required in addition to the ones necessary for innovation systems alone (Section 11.3.2).

\subsubsection{Assessing innovation systems: reviewing the state of the art}

Innovation systems display four major features which are crucial for assessing them. Innovative agents, i.e. those influencing research and innovation processes, include companies, universities, private and public research organizations, civic communities as well as governmental bodies, such as ministries or city councils (Bergek, Jacobsson, Carlsson, Lindmark, \& Rickne, 2008; Edquist, 2011; Klein Woolthuis, Lankhuizen, \& Gilsing, 2005). Innovative agents' communication and collaboration with partners form their relationships. These relationships depend on how close (potential) collaboration partners are to each other in cognitive, organizational, personal, social, institutional and geographical terms (Boschma, 2005; Caniëls, Kronenberg, \& Werker, 2014; Werker, Ooms, \& Caniëls, 2016). Innovative agents can support and use formal (e.g. laws and regulations) and informal institutions (e.g. codes of conducts) which can either enable or hinder innovation processes (Bergek et al., 2008; Edquist, 2011; Werker et al., 2016). Innovative agents' activities, i.e. how they organize research and innovation, are crucial to understand the drivers of change in innovation systems (Bergek et al., 2008; Werker, 2001). While innovation systems display structural regularities such as management or policy processes, 
innovation processes themselves are inherently uncertain (Schwerin \& Werker, 2003). All four major features mentioned above may change in time, thereby influencing each other's evolution.

Assessing an innovation system means identifying opportunities and problems regarding the above-mentioned four features. To come to terms with this in a practical manner, a number of schemes have been provided (Bergek et al., 2008; Edquist, 2011; Klein Woolthuis et al., 2005). All of these schemes include the structural components of innovation systems, i.e. innovative agents, their relationships as well as formal and informal institutions. Some emphasize activities (Edquist, 2011), called functions by Bergek et al. (2008), thereby also focusing on the dynamics of innovation systems, i.e. co-evolution between innovative agents, their relationships and the supporting institutions. In Figure 11.1, I provide a scheme capturing the structural elements and the processes of innovation systems comprising the following five steps:

I. identifying the structural components, i.e. innovative agents, relationships and institutions (Klein Woolthuis et al., 2005)

II. finding crucial activities, such as knowledge advance by and diffusion amongst stakeholders, entrepreneurial experimentation, legitimation, market formation, development of institutions and influence on the direction of search by different selection mechanisms, such as business models, technology development, market and institutional forces (Bergek et al., 2008; Edquist, 2011)

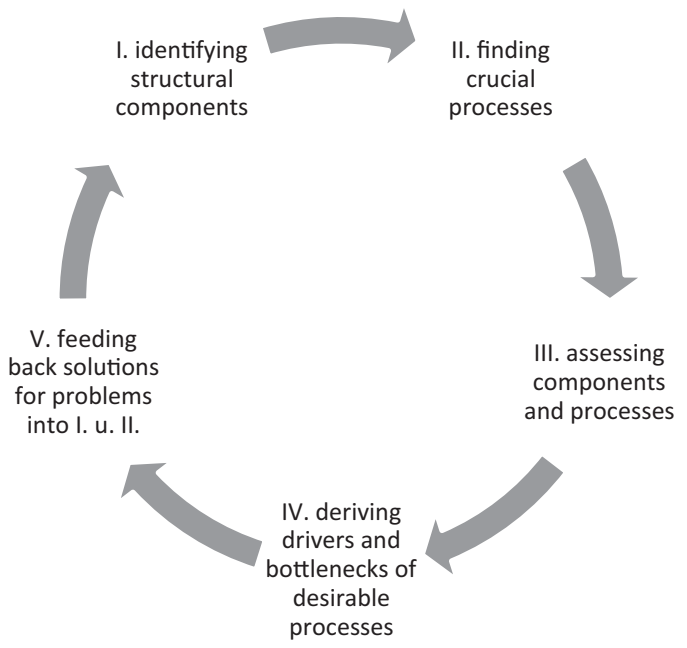

Figure 11.1 A scheme for assessing innovation systems. 
III. assessing components and processes by uncovering desirable ones (Bergek et al., 2008; Edquist, 2011; Klein Woolthuis et al., 2005)

IV. deriving drivers and bottlenecks of desirable components and processes (Bergek et al., 2008; Edquist, 2011; Klein Woolthuis et al., 2005)

V. feeding back solutions for problems into the structural components (I) and processes (II) including their functioning and co-evolution.

In the list below, I summarize the potential problems for which solutions have to be fed back into the next cycle of the innovation system. They can be related to either structural components (Klein Woolthuis et al., 2005), i.e. 1-4 in the list below, or activities (Bergek et al., 2008; Edquist, 2011), i.e. $5-10$ in the list below:

1. innovative agents facing lack of capability so that they are not able to obtain, create or use knowledge and innovation sufficiently

2. missing innovative agents that would be important for the functioning of the system, e.g. no business angels providing finance and advice for start-ups

3. problems in collaborating, i.e. lack of necessary relationships or too strong relationships leading to lock-ins

4. problems because of wrong or missing formal or informal institutions, e.g. missing standards

5. lack of knowledge development

6. lack of knowledge diffusion amongst stakeholders

7. missing entrepreneurial experimentation

8. no or insufficient legitimation

9. lacking market formation

10. insufficient processes to search for a sufficient variety of business models and technology solutions.

The ten problems summarized above lead agents and stakeholders of innovation systems to challenges they need to address in the future. To do so effectively and efficiently they need a qualification or quantification of the problems in the form of indicators. These indicators help them to assess the problem, develop solutions and measures as well as control whether the measures they take have effect.

For many of the potential problems, there exist rather straightforward quantitative indicators: data on patents, patent citations, licences, publications or publication citations (Nelson, 2009) can measure the knowledge capability of innovative agents (1). Moreover, when using them to compare different innovation systems they might point at a lack of knowledge development (5) or wanting diffusion amongst innovative agents (6). Problems of missing innovative agents (2) might be detected by indicators such as venture capital investment (e.g. EU Commission, 2018a). Problems of collaborating (3) might be captured by using the indicator of innovative 
small and medium-sized enterprises (SMEs) collaborating with others (e.g. EU Commission, 2018a). Problems of missing entrepreneurial experimentation (7) might show when looking at the indicators SMEs product/process innovations, SMEs marketing/organizational innovations and SMEs innovating in-house (e.g. EU Commission, 2018a). Insufficient processes to search for a sufficient variety of business models and technology solutions (10) could be measured by the newly defined indicators product innovation, i.e. "a new or improved good or service that differs significantly from the firm's previous goods or services and that has been introduced on the market" (OECD/Eurostat, 2018, p. 34), and business process innovation, i.e. "a new or improved business process for one or more business functions that differs significantly from the firm's previous business processes and that has been brought into use by the firm" (OECD/Eurostat, 2018, p. 34).

For other problems mentioned above the combined use of quantitative and qualitative indicators is necessary: Insufficient legitimation, i.e. not fully abiding by the innovative agents' norms and values (8), can be overcome by conscious processes of changing institutions or finding solutions within existing ones (4) (Bergek et al., 2008). Lacking market formation (9) requires the analysis of the different market phases, of the users, their preferences and their purchasing processes as well as of the institutions, particularly whether they stimulate market formation or if they need to change to do so (Bergek et al., 2008). The respective indicators are partly readily available quantitative facts on market size and on customer groups and partly qualitative data, e.g. stakeholders' strategies (Bergek et al., 2008).

Often indicators are combined and compared in order to identify whether or not individual innovative agents or whole systems, e.g. national innovation systems, perform well or not (e.g. EU Commission, 2018a). The combined use of indicators requires the weighing of the underlying indicators and might lead to tuned and unreliable rankings (Grupp \& Schubert, 2010). Recently, the well-established European Innovation Scoreboard (EU Commission, 2018a) was severely criticized for not carefully reflecting on the use of input and output indicators in their analysis, because it mixes input and output innovation indicators and uses their average without defining and theoretically underpinning the meaning of innovation performance. According to Edquist, Zabala-Iturriagagoitia, Barbero, and Zofío (2018) this makes their interpretations and the ranking of European Union (EU) innovation systems misleading and worthless. So, while this combined use of indicators to rank innovation systems is well established, it has to be done with care. Otherwise it might be misleading.

\subsubsection{Assessment of RRI systems: adding responsibility to the mix}

To develop an RRI system approach we need to extend the innovation system approach with responsibility. In order to do so we have to include the following aspects to our analysis. First of all, we have to identify 
those stakeholders who are affected by research and innovation and do not have any influence on innovation processes and design. In contrast to innovative agents, those stakeholders are usually left out of the analysis of innovation systems. On the rather rare occasion those stakeholders are included in the analysis they are just described as collaterals whose values are not integrated in the process and design. In order to make innovation responsible all stakeholders affected by research and innovation processes including their values have to be included in the analysis (see also Section 11.2). So, the first step in the assessment scheme of RRI systems has to change accordingly (Figure 11.2). Second, responsible innovations are only possible when research and innovation processes lead to designs appropriately incorporating shared values (Taebi et al., 2014; van de Poel, 2009). So, developing these shared values has to be part of the second step of the assessment scheme. Moreover, in the third step the processes and outcomes of the RRI system would be assessed on the basis of these shared values. In the fourth step when the drivers and bottlenecks of desirable processes are identified additional value-related drivers and bottlenecks might occur. This might lead to additional opportunities as value-related drivers might lead to much more acceptance of the RRI amongst all stakeholders. Yet failure to develop shared values might lead to exactly the opposite. In the fifth step when solutions to the identified problems are chosen shared values might help to choose between various opportunities. In some cases it is possible to come up with a solution that is an improvement for everyone or an improvement for some with the situation being the same for the rest of the

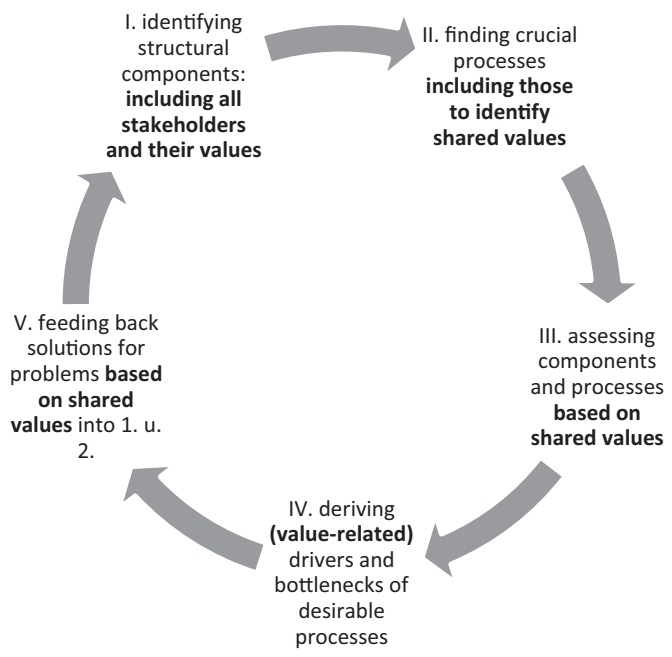

Figure 11.2 A scheme for assessing Responsible Research and Innovation (RRI) systems. 
stakeholders. In other cases stakeholders need to find ways to compensate those worse off because of the innovation process (Taebi et al., 2014). In doing so the relationships between stakeholders as well as institutions might change, thereby also substantially changing the assessment of innovative processes and design.

To assess RRI systems, we have to add four more potential problems to the already existing list regarding innovation systems (Section 11.3.1). Yet these problems do also exist when not taking the RRI perspective. They are simply not acknowledged and might lead to severe acceptance problems, such as with the Dutch electronic patients' card which eventually fell through parliament because of privacy concerns that had not been sufficiently taken into consideration early on in developing these cards (Von Schomberg, 2013). The potential additional problems are:

11. problems in including all stakeholders (a) and all their values (b), e.g. accounting for environmental damage that will affect future generations

12. lack of adequate processes to communicate and collaborate in order to develop shared values

13 failure to compensate those stakeholders worse off because of an RRI

14. inability to base decisions on how to choose solutions for problems identified on shared values.

In order to detect the four additional problems summarized above as well as to develop solutions and measures that can be assessed we need additional indicators. While the information on all relevant stakeholders (11a) might be readily available - at least for experts in the field of the respective RRI - getting a clear picture on all their values (11b) might turn out to be difficult. In academic settings mid-stream modulation leads to a situation where individual researchers are more aware and reflect more on the social and ethical aspects of their work (Flipse, Sanden, \& Osseweijer, 2013). This higher reflective awareness might be used to collect information on values in other settings as well. Another way to identify values was suggested by van de Poel et al. (2017). When companies translate their RRI strategy into activities resulting in RRI outcomes they could also develop company-specific RRI key performance indicators to assess their performance. The lack of adequate processes to communicate and collaborate in order to develop shared values (12) might be detected by an "embedded humanist" carrying out a mid-stream modulation (Flipse et al., 2013) but would require constant supervision by a third party. The same holds for the failure to compensate those stakeholders worse off because of an RRI (13) as well as the inability to base decisions on how to choose solutions for problems identified on shared values (14). A way out might be to choose indicators on a much more aggregated level, e.g. by uncovering whether research-performing organizations and research-funding organizations have and apply ethical guidelines (Mejlgaard, Bloch, \& Madsen, 2018). Yet this 
does not indicate whether values are appropriately included, developed into shared ones and applied to the decision process when solving problems in the case of specific RRIs.

\subsection{Assessing RRI systems in the digital age}

The digital age comes with various opportunities and challenges, two of which are crucial for the assessment for RRI systems, i.e. big data and internet of things (IoT) platforms (Section 11.4.1). In Section 11.4.2 I will enhance the scheme of assessing RRI systems (see Section 11.3.2) by including opportunities and challenges of the digital age, as identified in Section 11.4.1.

\subsubsection{The digital age: big data analytics and IoT platforms}

There are two core elements of the digital age that have the potential to influence RRI systems substantially. The first element is big data, which changes the playing field of assessing RRI systems because of its very nature. The second is the IoT platforms which offer opportunities of connecting RRI systems.

\subsubsection{Big data analytics}

The digital age is driven by so-called big data and most particularly its analysis. Often large amounts of digitized information are defined as big data. Data, i.e. Latin for "things given" to us, stem from various sources, e.g. nature, careful observation or people (Jacobs, 2009). While chatting, shopping and connecting with platforms, we produce data (IDC, 2016; Loebbecke \& Picot, 2015). Those of us wearing sensors, e.g. collecting heart rate measurement and number of steps walked, or blogging, add to this enormous amount of data even more (Porter \& Heppelmann, 2014).

What makes most big data big is repeated observations over time and/ or space. The Web log records millions of visits a day to a handful of pages; the cellphone database stores time and location every 15 seconds for each of a few million phones; the retailer ... logs billions and billions of individual transactions in a year. Scientific measurements are often made at a high time resolution (thousands of samples a second in neurophysiology, far more in particle physics) .. [They] really start to get huge when they involve two or three dimensions of space as well; [e.g. in] neuroimaging.

$$
\text { (Jacobs, 2009, p. 5) }
$$

While the sheer amount of data, i.e. its volume, is often used to define big data, there is much more to it. First of all, velocity and variety characterize big data as well (Erevelles, Fukawa, \& Swayne, 2016; Galbraith, 2014). 
Velocity points at the quick availability sometimes connected with big data. Variety captures the fact that big data usually stems from numerous sources, because it often combines both structured transactional data, e.g. from files or sensors, with unstructured behavioural data, e.g. from blogs or text messages. Second, to use big data stakeholders need big data analytics, i.e. "analytical techniques in applications that are so large (from terabytes to exabytes) and complex (from sensor to social media data) that they require advanced and unique data storage, management, analysis, and visualization technologies" (Chen, Chiang, \& Storey, 2012, p. 1166).

Using big data analytics comes with numerous challenges both in practical terms and in terms of values. In practical terms the challenges emerge from the necessity to digitize, align, analyse and store big data (Galbraith, 2014; Kshetri, 2014). Stakeholders in RRI systems have to acknowledge and overcome these practical challenges to understand big data and the consequences of its use so that they can possibly use it for their own purposes. In terms of integrating all stakeholders of RRI systems into the processes of research and innovation this might become an additional challenge, as some of the stakeholders might be much better equipped with the capacities and financial means to engage in big data analytics than others, giving them an information advantage in the RRI processes.

In terms of values the characteristics of big data and the use of big data analytics lead to challenges with regard to privacy and security issues as well as concerns regarding welfare, discrimination and strategic behaviour. Analysing big data means that huge amounts of data from different sources, including unstructured data, e.g. from blogs, often collected and processed in real time are used to act and react (cf. this and the following Kshetri, 2014; Sogeti, 2013). Most organizations lack mechanisms of using and protecting unstructured data sufficiently, thereby creating privacy and security issues. Outsourcing data to cloud service suppliers comes with even more privacy and security issues, because it makes the process of data collection, storage and use even more complex. In addition, the process of how big data is collected, analysed and used is often not sufficiently transparent. So, the owners of the data, often private entities such as consumers or patients, do not get the chance to give informed consent to participate. Frequently they are even not aware that the combination of various kinds of sources makes it more likely that personal identifiable information about them is revealed. This can lead to welfare losses. While nowadays consumers have the chance to hide how much they are willing to pay for a specific product and are usually asked the same price as everyone else buying the product, in the digital world they might undergo price discrimination, because the seller of the product collected, combined and used a lot of data to find out how much they are willing to pay.

The consequences of personal identifiable information falling into the wrong hands can be even more severe. In cases where location-based realtime personal information is used this might lead to stalking in real time. 
Moreover, while data-driven technologies have often been viewed as positive, they might enhance discriminatory biases, e.g. by embedding algorithms in data-driven technologies used for screening potential incoming students, discriminating against women or people with non-European names (Niklas \& Pena Gangadharan, 2018). In addition, the nature of big data might inherently alter the exchange between stakeholders. It is known that stakeholders might react strategically to assessment (Freeman \& Soete, 2009; van de Poel et al., 2017). As big data is often available in real time (Galbraith, 2014), this problem becomes much bigger, because we might even lose the information of how non-strategic behaviour would have looked like. It will become a challenge to determine shared values under such circumstances.

While big data analytics has been subject to severe concerns, at the same time, it might offer new ways of assessing RRI systems. Nowadays, big data analytics often drives new solutions in research and innovation. In these cases it also provides additional and appropriate ways in creating new indicators to identify opportunities and challenges in the respective RRI systems. Take the health sector where the well-established gender bias in treatment of women still has to be overcome (Hamberg, 2008). While there have been numerous studies on gender bias regarding cardiovascular disease, follow-up protocols about medical treatment and outcome by gender still need to be evaluated more carefully. By using big data analytics physicians and pharmacists can assess huge volumes of information on who is getting and using which drugs under what circumstances (healthworkscollective.com, 2014). Based on this they can design and implement optimal drug therapies - also for women. So, big data, in this example, provides the stakeholders in the RRI system with a solution for a problem identified as the shared value of gender equity in health care (step V along the lines of the scheme depicted in Figure 11.3).

Another example is autonomous driving. While huge amounts of data from different sources will help to make traffic much safer (PWC \& Flanders Make, 2017), it does not make it $100 \%$ safe. So, in principle the well-established trolley problem of whom to hurt or kill - when you do not have the option of hitting no one, remains (Nyholm \& Smids, 2016). Yet big data does not only help advancing safety in traffic it also provides those involved in the respective RRI system with much better and more detailed information to make the value choices involved. This example shows that big data might help to identify shared values in step II and use them along the lines of the scheme depicted in Figure 11.3.

While big data might help to identify shared values and deal with them in the RRI process, there need to be both appropriate data available and institutions in place to guard their use in the RRI process. Data about technologies that are almost readily available will usually suffice to support RRI processes. Yet for technologies in the beginning of their development this might not be the case. Moreover, the values of minorities, of relatively powerless groups of stakeholders or of future generations might be underrepresented. It is a typical task of governmental agencies to either 


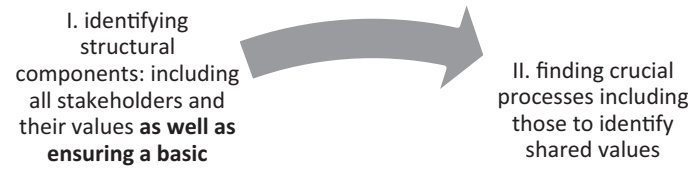

digital literacy of all parties involved

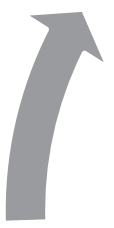

shared values

. feeding back big data and loT based

solutions for problems

based on shared

values into 1. u. 2.

III. assessing components and processes based on shared values with the help of big data analysis controlling for privacy and security issues, fair welfare distribution, strategic behaviour and biases
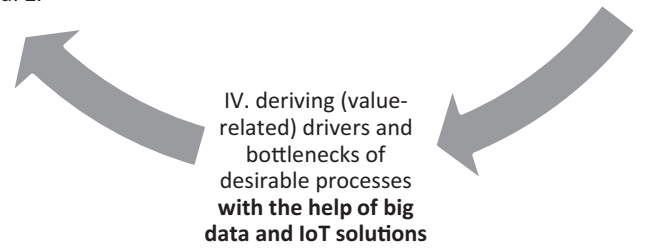

Figure 11.3 A scheme for assessing Responsible Research and Innovation (RRI) systems in the digital age.

Note: IoT, internet of things.

represent them or to make sure that the institutions suffice to have them represented appropriately.

\subsubsection{IoT platforms}

Important elements of the digital age are the IoT platforms which allow "communication between humans as well as machines in Cyber-PhysicalSystems (CPS) throughout large networks" (Brettel, Friederichsen, Keller, \& Rosenberg, 2014, p. 37). This does not only change industrial production processes, often subsumed under the title industry 4.0 (Brettel et al., 2014), but has the potential to change the situation for all stakeholders in RRI systems. Already modern communication had changed the way collaboration partners organize and maintain ties (Genoni, Merrick, \& Willson, 2005; Haythornthewait, 2002; Rychen \& Zimmermann, 2008). Putting IoT platforms to use to organize RRI processes, particularly taking on board all stakeholders of the RRI system, would give ample opportunities to change communication patterns. To give an example, it would be much more 
difficult to justify why stakeholders other than innovative agents would not be included in the process as IoT platforms would make it much easier. The EU Commission and other governmental bodies are already making use of this possibility by providing webpages where interested parties can give their input for new initiatives (EU Commission, 2018b). In addition, IoT platforms could be used to supervise RRI processes by following the communication partners on these platforms.

While using communication data might lead to strategic behaviour and might come with privacy or security concerns (see discussion above), it also means that the person or organization mediating the RRI process about how and when stakeholders contact each other and what kind of information they exchange has much more information. This might give them much more detailed insights into the technological, innovative and ethical aspects of the exchanges, thereby giving them the opportunity to influence the communication within RRI systems to overcome a lack of adequate processes to communicate and collaborate in order to develop shared values (problem 12 as identified in Section 11.3.2). This would mean that the values of all stakeholders would be better included and better aligned to technological opportunities emerging.

\subsubsection{Assessing RRI systems in the digital age: a scheme}

Assessing RRI systems in the digital age requires to consider its challenges and to use its opportunities. In Figure 11.3, I add the major opportunities and challenges of the digital age to the scheme provided for the assessment of RRI systems in Figure 11.2.

In the course of the digital age all stakeholders have to get some understanding of how the digitization, alignment, analysis and storage of big data take place and of how IoT platforms work (see Section 11.4.1). Stakeholders less digitally educated, less wealthy and less powerful than other stakeholders in an RRI system will have a hard time dealing with the opportunities and challenges of the digital age and will most likely fall behind (Bloem et al., 2013). This opens ample opportunity for governmental, academic and civic agents to step up by educating and involving these disadvantaged stakeholders (see step $\mathrm{I}$ in Figure 11.3). As big data has been driving big science, i.e. data-driven solutions in research, e.g. at CERN (Bloem et al., 2013), we might expect that the values emerging from, in this case, the academic sector, might already include goals of inclusiveness and enabling people by educating them. As long as an RRI system is not dominated by profit-oriented organizations only there is a good chance that the RRI process will lead to shared values, providing a level playing field in the RRI system.

When using big data analytics in RRI systems stakeholders have to be aware of privacy and security issues as well as concerns regarding welfare, discrimination and strategic behaviour (see Section 11.4.1). After having determined the structural components and the processes of the RRI system at 
hand it is therefore crucial to address these potential issue in the assessment of them in step III of Figure 11.3.

Currently, big data and its analytical tools are often the driver of new solutions in RRI systems. They come with new indicators to identify the opportunities and challenges in the RRI system they drive (see Section 11.4.1). Moreover, IoT platforms could be used to better include all stakeholders of RRI systems into the RRI process as well as better mediating this process (see Section 11.4.1), e.g. identifying capability problems of innovative agents (problem 1) or missing entrepreneurial experimentation (problem 7). As many of the problems mentioned in Section 11.3 could be identified and potentially solved by big data analytics and IoT solutions, they can be important elements in deriving (value-related) drivers and bottlenecks of desirable process in step IV of Figure 11.3. The same holds for feeding back possible solutions into the next round of the scheme in step $\mathrm{V}$ of Figure 11.3, which might also benefit from big data and IoT solutions. While big data and IoT solutions come with numerous potential concerns, including them in the RRI process should help to overcome them. For example, companies have the opportunity to offer big data-driven solutions that protect personally identifiable information by privacy by design, i.e. being transparent about what they do, complying with the wishes of the customers regarding privacy and explaining as much as possible about what they do with their data (Bloem et al., 2013).

\subsection{Conclusions}

As the digital transformation of our societies including RRI systems will take off even more in coming years, more consequences might emerge in the future. In order to assess RRI in the digital age we need a system approach, because RRI emerges from the co-evolution of stakeholders, their relationships and activities as well as the supporting institutions (see Sections 11.2 and 11.3). Moreover, we have to acknowledge and use the opportunities and challenges emerging from the digital transformation which changes the playing field of RRI systems substantially (see Section 11.4).

So far, we can derive three major lessons for the assessment of RRI systems in the digital age. First of all, in order to create a level playing field in the RRI process it is important that all stakeholders have at least some understanding of how the digitization, alignment, analysis and storage of big data take place and of how IoT platforms work. This will help them to assess their situation and act accordingly. Second, all stakeholders have to understand that ignoring or suppressing the values of other stakeholders involved will lead to complications along the process. So, it is important to be aware of and to acknowledge the privacy and security issues as well as concerns regarding welfare, discrimination and strategic behaviour of all stakeholders involved. Third, big data analytics and IoT platforms are more often than not giving the tools for assessing and maintaining RRI systems. 
Big data analytics often drive new solutions in RRI systems and provide indicators to assess the related opportunities and challenges. Moreover, IoT platforms could be used to better include all stakeholders of RRI systems into the RRI process as well as better mediating this. Therefore, big data analytics and IoT solutions can be important in governing RRI processes.

Values are core to the evolution and assessment of RRI systems. Therefore, it is crucial that stakeholders from all sectors, i.e. government, academia, industry and civic society, have a clear picture of their own values, how they change in time, what the values of other stakeholders in their RRI system look like and what opportunities and ways there are to develop shared ones. In the digital age research and innovation offer an abundance of opportunities to solve commercial, economic and societal problems responsibly. How stakeholders of RRI systems assess them and how they deal with the challenges will to a large extent determine how our society will look in the future.

By using shared values as the cornerstone to assess the components and activities of RRI systems the question of which activities are welcome or not in a society can be answered on the micro-level. The use of shared values requires that all stakeholders eventually agree on them. Yet it opens up the more fundamental question of how the direction and intensity of innovative activities (Cantner \& Vannuccini, 2018) are related to the development of shared values. As long as we have a clear view on the various options RRI opens up in the future - which is a non-trivial problem as such - shared values can guide us in finding jointly acceptable directions of innovative activities. Yet shared values do not provide any objective criteria of the "right" intensity of innovative activities - a problem possibly only solvable by experimentation. Clarifying the relationship between shared values on the one hand and the direction and intensity of innovation activities on the other hand might open up a perspective on innovation policy that goes beyond market or system failure approaches. This is subject to further research.

\section{References}

Bergek, A., Jacobsson, S., Carlsson, B., Lindmark, S., \& Rickne, A. (2008). Analyzing the functional dynamics of technological innovation systems: A scheme of analysis. Research Policy, 37(3), 407-429. doi:10.1016/j.respol.2007.12.003

Bloem, J., van Doorn, M., Duivestein, S., van Manen. T., van Ommeren, E., \& Sachdeva, S. (2013). No More Secrets with Big Data Analytics (pp. 206). Groningen: Sogeti. ISBN: 9789075414738.

Boschma, R. (2005). Proximity and innovation: A critical assessment. Regional Studies, 39(1), 61-74. doi:10.1080/0034340052000320887

Brettel, M., Friederichsen, N., Keller, M., \& Rosenberg, M.(2014). How Virtualization, Decentralization and Network Building Change the Manufacturing Landscape: An Industry 4.0 Perspective. Retrieved from: http://waset.org/publications/9997144

Caniëls, M. C. J., Kronenberg, K., \& Werker, C. (2014). Conceptualizing proximity in research collaborations. In R. Rutten, P. Benneworth, D. Irawati, \& F. Boekma 
(Eds.), The Social Dynamics of Innovation Networks (pp. 221-238). London: Routledge.

Cantner, U., \& Vannuccini, S. (2018). Elements of a Schumpeterian catalytic research and innovation policy. Industrial and Corporate Change, 27(5), 833-850. doi:10.1093/icc/dty028

Chen, H., Chiang, R. H. L., \& Storey, V. C. (2012). Business intelligence and analytics: From big data to big impact. MIS Quarterly, 36(4), 1165-1188.

Edquist, C. (2011). Design of innovation policy through diagnostic analysis: Identification of systemic problems (or failures). Industrial and Corporate Change, 20(6), 1725-1753. doi:10.1093/icc/dtr060

Edquist, C., Zabala-Iturriagagoitia, J. M., Barbero, J., \& Zofío, J. L. (2018). On the meaning of innovation performance: Is the synthetic indicator of the Innovation Union Scoreboard flawed? Research Evaluation, 27(3), 196-211. doi:10.1093/ reseval/rvy011

Erevelles, S., Fukawa, N., \& Swayne, L. (2016). Big data consumer analytics and the transformation of marketing. Journal of Business Research, 69(2), 897-904. doi:10.1016/j.jbusres.2015.07.001

Etzkowitz, H., \& Viale, R. (2010). Polyvalent knowledge and the entrepreneurial university: A third academic revolution? Critical Sociology, 36(4), 595-609. doi:10.1177/0896920510365921

EU Commission. (2018a). European Innovation Scoreboard. Retrieved from: https:// op.europa.eu/en/publication-detail/-/publication/8e458033-74fc-11e8-948301aa75ed71a1/language-en/format-PDF/source-99539237

EU Commission. (2018b). Have your Say. Retrieved from: https://ec.europa.eu/info/ law/better-regulation/have-your-say_en

European Commission. (2012). A European Strategy for Key Enabling Technologies A Bridge to Growth and Jobs. Retrieved from: http://eur-lex.europa.eu/LexUriServ/ LexUriServ.do?uri=COM:2012:0341:FIN:EN:PDF

European Commission. (2013). Options for Strengthening Responsible Research and Innovation. Luxembourg: European Commission.

Flipse, S., Sanden, M. A., \& Osseweijer, P. (2013). Midstream modulation in biotechnology industry: Redefining what is 'part of the job' of researchers in industry. Science and Engineering Ethics, 19(3), 1141-1164. doi:10.1007/ s11948-012-9411-6

Forsberg, E.-M., Shelley-Egan, C., Ladikas, M., \& Owen, R. (2018). Implementing Responsible Research and Innovation in research funding and research conducting organisations - what have we learned so far? In F. Ferri, N. Dwyer, S. Raicevich, P. Grifoni, H. Altiok, H. T. Andersen, Y. Laouris, \& C. Silvestri (Eds.), Governance and Sustainability of Responsible Research and Innovation Processes (pp. 111). Springers Brief in Research and Innovation Governanc, Springer, Cham (Switzerland). https://doi.org/10.1007/978-3-319-73105-6_1

Freeman, C., \& Soete, L. (2009). Developing science, technology and innovation indicators: What we can learn from the past. Research Policy, 38, 583-589. doi:10.1016/j.respol.2009.01.018

Galbraith, J. R. (2014). Organizational design challenges resulting from big data. Journal of Organization Design, 3(1), 2. doi:10.7146/jod.8856

Gebauer, J., Füller, J., \& Pezzei, R. (2013). The dark and the bright side of cocreation: Triggers of member behavior in online innovation communities. 
Journal of Business Research, 66(9), 1516-1527. doi: https://doi.org/10.1016/ j.jbusres.2012.09.013

Genoni, P., Merrick, H., \& Willson, M. (2005). The use of the internet to activate latent ties in scholarly communities. First Monday, 10(12). doi: http://dx.doi.org/ 10.5210/fm.v10i12.1301

Grupp, H., \& Schubert, T. (2010). Review and new evidence on composite innovation indicators for evaluating national performance. Research Policy, 39(1), 6778. doi:10.1016/j.respol.2009.10.002

Hamberg, K. (2008). Gender bias in medicine. Women's Health, 4(3), 237-243. Retrieved from: http://journals.sagepub.com/doi/pdf/10.2217/17455057.4.3.237

Haythornthewait, C. (2002). Strong, weak, and latent ties and the impact of new media. The Information Society, 18, 385-401. doi:10.1080/0197224029010819

healthworkscollective.com. (2014). Five Ways Big Data is Improving Patient Outcomes. Retrieved from: www.healthworkscollective.com/ways-big-data-healthcare-improvingpatient-outcomes/

IDC. (2016). Industrial Data Platforms - Key Enablers of Industry Digitization. Retrieved from: www.key4biz.it/wp-content/uploads/2018/04/SMART20130063_ Final-Report_030417_2.pdf

Jacobs, A. (2009). The pathologies of big data. ACM Queue, 2014, 1-12. Retrieved from: http://queue.acm.org/detail.cfm?id=1563874

Klein Woolthuis, R., Lankhuizen, M., \& Gilsing, V. (2005). A system failure framework for innovation policy design. Technovation, 25(6), 609-619. doi:10.1016/ j.technovation.2003.11.002

Kshetri, N. (2014). Big data's impact on privacy, security and consumer welfare. Telecommunications Policy, 38(11), 1134-1145. doi:10.1016/j.telpol.2014. 10.002

Loebbecke, C., \& Picot, A. (2015). Reflections on societal and business model transformation arising from digitization and big data analytics: A research agenda. Journal of Strategic Information Systems, 24, 149-157. doi:10.1016/j.jsis. 2015.08.002

Mejlgaard, N., Bloch, C., \& Madsen, E. B. (2018). Responsible research and innovation in Europe: A cross-country comparative analysis. Science and Public Policy. doi:10.1093/scipol/scy048

Mitchell, R. K., Agle, B. R., \& Wood, D. J. (1997). Toward a theory of stakeholder identification and salience: Defining the principle of who and what really counts. Academy of Management Review, 22(4), 853-886. doi:10.5465/ amr.1997.9711022105

Nelson, A. J. (2009). Measuring knowledge spillovers: What patents, licenses and publications reveal about innovation diffusion. Research Policy, 38(6), 9941005. doi:10.1016/j.respol.2009.01.023

Niklas, J., \& Pena Gangadharan, S. (2018). Data-driven Discrimination: A New Challenge for Civil Society. London: London School of Economics Impact Blog.

Nyholm, S., \& Smids, J. (2016). The ethics of accident-algorithms for self-driving cars: An applied trolley problem? Ethical Theory and Moral Practice, 19(5), 1275-1289. doi:10.1007/s10677-016-9745-2

OECD/Eurostat. (2018). Oslo Manual 2018. Retrieved from www.oecd-ilibrary.org/ docserver/9789264304604-en.pdf? expires $=1599730730 \& i d=i d \&$ accname $=$ guest \&checksum=3CEF6403AC7338FF492B28799B5117BF 


\section{Claudia Werker}

Porter, M. E., \& Heppelmann, J. E. (2014). How smart, connected products are transforming competition. Harvard Business Review(November), 1-23.

PWC, \& Flanders Make. (2017). Industry 4.0: Hype or Reality? Retrieved from: www.pwc.be/en/news-publications/publications/2017/industry-hype-orreality.html

Rychen, F., \& Zimmermann, J.-B. (2008). Clusters in the global knowledge-based economy: Knowledge gatekeepers and temporary proximity. Regional Studies, 42(6), 767-776. doi:10.1080/00343400802088300

Schwerin, J., \& Werker, C. (2003). Learning innovation policy based on historical experience. Structural Change and Economic Dynamics, 14(4), 385-404. doi:10.1016/s0954-349x(03)00031-6

Stilgoe, J., Owen, R., \& Macnaghten, P. (2013). Developing a framework for responsible innovation. Research Policy. doi:10.1016/j.respol.2013.05.008

Taebi, B., Correljé, A., Cuppen, E., Dignum, M., \& Pesch, U. (2014). Responsible innovation as an endorsement of public values: The need for interdisciplinary research. Journal of Responsible Innovation, 1(1), 118-124. doi:10.1080/ 23299460.2014.882072

van de Poel, I. R. (2009). Values in engineering design. In A. Meijers (Ed.), Philosophy of Technology and Engineering Sciences (pp. 973-1006). Amsterdam: Elsevier. www.sciencedirect.com/science/article/pii/B9780444516671500409

van de Poel, I., Asveld, L., Flipse, S., Klaassen, P., Scholten, V., \& Yaghmaei, E. (2017). Company strategies for Responsible Research and Innovation (RRI): A conceptual model. Sustainability, 9(11), 2045. doi:10.3390/su9112045

Von Schomberg, R. (2013). A vision of Responsible Research and Innovation. In R. Owen, M. Heintz, \& J. Bessant (Eds.), Responsible Innovation (51-74). London: John Wiley.

Werker, C. (2001). Knowledge and organisation strategies in innovation systems. International Journal of Innovation Management, 5(1), 105-127. https://doi.org/ 10.1142/S1363919601000300

Werker, C., Ooms, W., \& Caniëls, M. C. J. (2016). Personal and related kinds of proximity driving collaborations: a multi-case study of Dutch nanotechnology researchers. SpringerPlus, 5(1). doi:10.1186/s40064-016-3445-1 